http://jmscr.igmpublication.org/home/ ISSN (e)-2347-176x ISSN (p) 2455-0450

crossref DOI: https://dx.doi.org/10.18535/jmscr/v7i12.45

\author{
Journal Of Medical Science And Clinical Research \\ IGM Publication \\ An Official Publication of IGM Publication
}

\title{
A case of Inflammatory Bowel Disease with Extra-Intestinal Manifestation
}

\author{
Authors \\ Uthaya Sankar M.K ${ }^{1}$, Mythreini B.S ${ }^{2}$, Louis Ferdin Zeno.. $\mathbf{J}^{3}$ \\ ${ }^{1}$ Professor, ${ }^{2,3}$ Post Graduate Residents \\ Department of General Medicine, Sri Manakula Vinayagar Medical College and Hospital, \\ Puducherry-605107, India
}

\begin{abstract}
Primary sclerosing cholangitis is an extra-intestinal manifestation of inflammatory bowel disease (IBD). About 5\% of ulcerative colitis develops primary sclerosing cholangitis. Here we report a case presented with chronic loose stools and jaundice and was diagnosed to have Ulcerative colitis with associated Primary sclerosing cholangitis.
\end{abstract}

\section{Introduction}

Inflammatory bowel disease is characterised by immune mediated chronic intestinal condition. Ulcerative colitis and crohns disease are the two major forms. It can also affect other systems. Diseases of the liver and biliary tract are common extra-intestinal manifestation of IBD. Primary sclerosing cholangitis is one of the most common manifestation. Approximately $5 \%$ of patients with ulcerative colitis develop primary sclerosing cholangitis. ${ }^{1}$

\section{Case Report}

32 year old male presented with complaints of loose stools since 3 years, more in the night, which was yellow in colour and semisolid in consistency and was associated with mucus and sometimes mixed with blood with history of urgency. History of yellowish discolouration of eye was present for the past 1 year. History of itching and light coloured stools present. No other significant history. On examination patient had icterus.
Blood investigations showed elevated ESR and cholestatic pattern of derangement of liver profile. Ultrasound abdomen showed fatty liver and fibroscan showed a liver stiffness of $21 \mathrm{Kpa}$ which was increased. ANA was positive, p-ANCA was positive, Immunoglobulins were elevated. Sigmoidoscopy showed erythematous and friable of the entire mucosa with granularity and loss of vascularity in the sigmoid colon and rectum and pseudopolyps and normal anal canal. Biopsy was done and came as suggestive of ulcerative colitis (Fig 1). MRCP showed multiple focal areas of dilatation of the extrahepatic bile duct with irregularity of the duct wall and normal intrahepatic biliary radicles (Fig 2). So he was diagnosed as Ulcerative colitis with primary sclerosing cholangitis and started on prednisolone, mesalamine and urso deoxy cholic acid. 


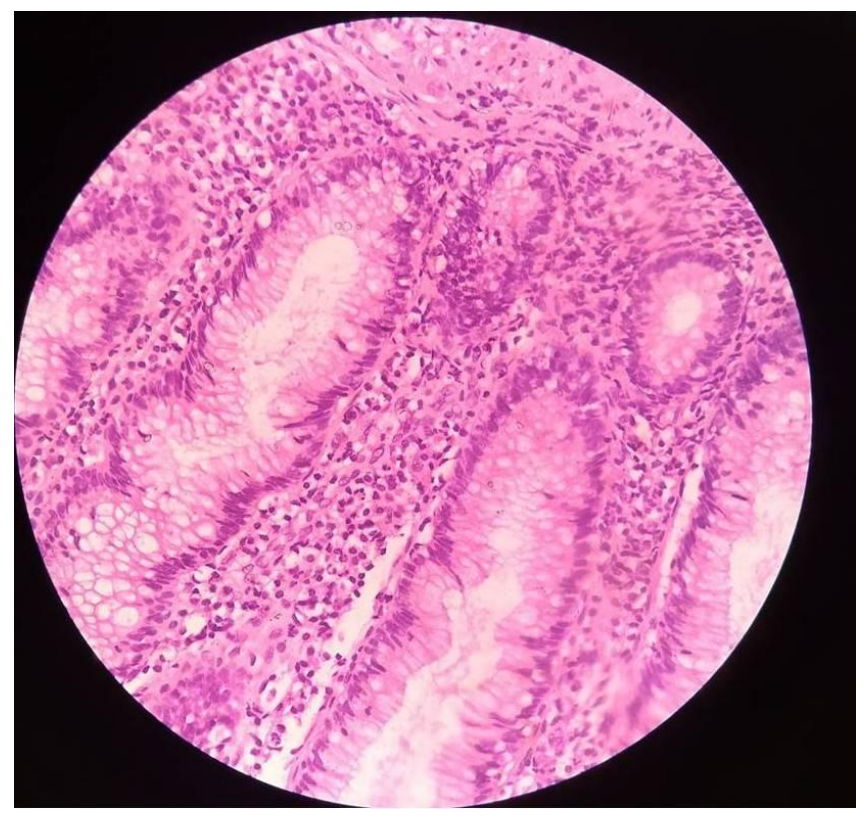

Fig 1: Biopsy of sigmoid colon showing dense lymphoplasmacytic infiltrate of lamina propria with neutrophilic infiltration of the crypts with crypt abscess.

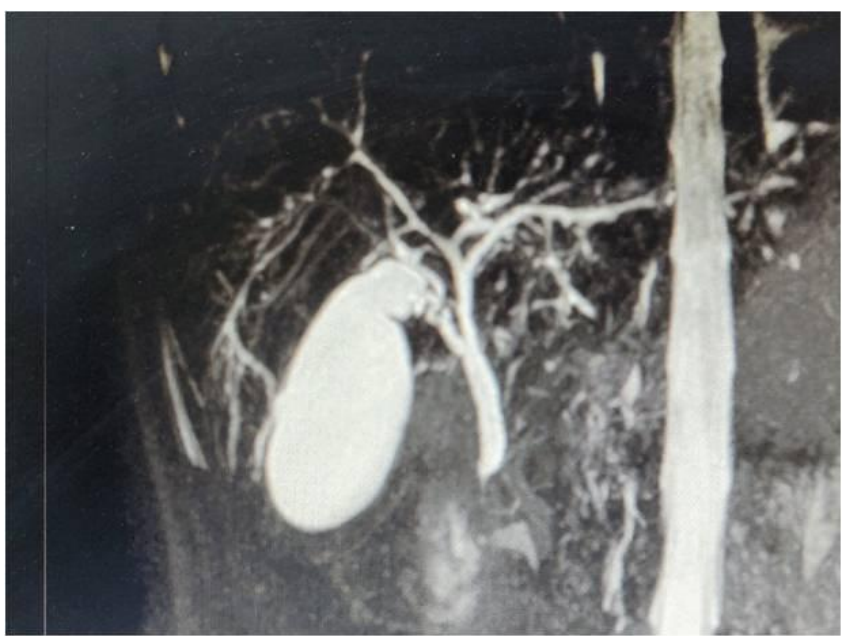

Fig 2: MRCP showing multiple focal areas of dilatation of extrahepatic bile duct.

\section{Discussion}

Primary sclerosing cholangitis is a disorder characterized by both intrahepatic and extrahepatic bile duct inflammation and fibrosis, frequently leading to biliary cirrhosis and hepatic failure. Approximately 5\% of patients with UC have PSC. $50-75 \%$ of patients with PSC have IBD(mostly Ulcerative colitis) ${ }^{2}$. Patients with IBD and PSC are at increased risk of colon cancer. There is no treatment that has been proven to be effective for treating PSC. However some clinical trials showed that long term use of Urso deoxy cholic acid therapy is associated with improvement in serum liver markers but does not improve the patient survival and improvement of symptoms ${ }^{3}$. Patients with end stage liver disease are advised for liver transplantation. The incidence of recurrent PSC is $20 \%$.

\section{References}

1. Kasper DL, Hauser SL, Jameson JL, Fauci AS, Longo DL, Loscalzo J. Harrison's principle of internal medicine. 20th ed. New York: The McGraw-Hill Companies; 2018.p.2431-32.

2. Mertz A, Nguyen NA, Katsanos KH, Kwok RM. Primary sclerosing cholangitis and inflammatory bowel disease comorbidity: an update of the evidence. Annals of gastroenterology. 2019 Mar;32(2):124.

3. Goode EC, Rushbrook SM. A review of the medical treatment of primary sclerosing cholangitis in the $21^{\text {st }}$ century. Therapeutics advances in chronic disease. 2016 Jan;7(1):68-85. 